\title{
Assessment of environmental safety in the influence zone of the current Zelenchukskaya HPP-PSPP and Krasnogorsky HPP-1, HPP-2 under construction in the area of Ust- Dzhegutinsky reservoir location
}

\author{
Vladimir Bondarenko ${ }^{1}$, Alla-Brerdi Ylyasov², Elena Semenova $^{3}$, Marat Mirzoev ${ }^{4}$ and \\ Maria Shtavdaker ${ }^{*}$ \\ ${ }^{1}$ Novocherkassk Engineering and Land Reclamation Institute named after A.K. Kortunov, Don State \\ Agrarian University, 346428, Novocherkassk, Russia \\ ${ }^{2}$ WTL branch (USA) in Asia, 119421, Moscow, Russia \\ ${ }^{3}$ Branch of the North Caucasus Federal University in Pyatigorsk. North Caucasus Federal University, \\ 357500, Pyatigorsk, Russia \\ ${ }^{4}$ LLC "Verkhnebalkarskaya MGES", Deputy General Director-Chief Engineer, 361813, Kabardino- \\ Balkar Republic, Russia
}

\begin{abstract}
Environmental safety" in the considered spatial limits of the basin geosystem of Upper Kuban $\left(\mathrm{F}_{\mathrm{w}}=11.0 * 103 \mathrm{~km}^{3}, \mathrm{~W}\right.$ lit. $=3.3 * 103 \mathrm{~km}^{3}$, $\mathrm{W}_{\mathrm{atm} .}=110 * 103 \mathrm{~W}$ BGUK $=124.3 * 103 \mathrm{~km}^{3}$ ) is about $21.4 \%$ of the spatial limits of the Kuban River, where water resources are formed according to the average long-term data of about $3.0 \mathrm{~km} 3$, which are used in various sectors of economic activity, including the generation of electric energy at the Zelenchukskaya HPP-PSPP and the Krasnogorsk HPP-1 and HPP-2 under construction with an installed capacity of up to $25 \mathrm{MW}$, located below the Zelenchukskaya HPP-PSPP target and above the target $(12 \mathrm{~km})$ UstDzhegutinsky reservoir. Such placement of the Zelenchukskaya HPP-PSPP and the Krasnogorsk HPP-1 and HPP-2 under construction on a $15 \mathrm{~km}$ long section of the Kuban Riverbed has determined a highly active zone of influence (IV), which is caused by a change in the natural hydrograph of the Kuban River, with the formation of an unstated hydraulic regime of the channel flow movement on the considered section of the river to the UstDzhegutinsky reservoir. The relentless changes in the water level in the UstDzhegutinsky reservoir affect the pressure safety front structures, the functional operation of the water intake hydroelectric complex in the Bolshoy Stavropol Canal (BSC) and the hydraulic operation of the BSC. To assess the "environmental safety" level, it became necessary to develop a mathematical model of the functional operation influence of the Zelenchukskaya HPP-PSPP and the Krasnogorsk HPP-1 and HPP-2 under construction on the Ust-Dzhegutinsky reservoir operation level modes.
\end{abstract}

\footnotetext{
* Corresponding author: shtawkader.marya@yandex.ru
} 


\section{Introduction}

Operating Zelenchukskaya HPP-PSPP introduces certain changes in the hydrological regime of water flow formation within the catchment area $\left(11,0 * 10^{3} \mathrm{~km}^{3}\right)$ in the river hydrographic network of the Upper Kuban $\left(\mathrm{W}_{\mathrm{BGUK}}=124,3 * 10^{3} \mathrm{~km}^{3}\right)$, as the dominant factor of "environmental safety". Based on the results of comprehensive studies of changes under the influence of the processes of interconnection, interaction and interrelation (III) natural (biotic, abiotic), social (living population) and technogenic (various types of hydraulic structures and related structures) components between themselves, the boundaries of the zones of influence were determined within the considered spatial limits of the basin geosystem of the Upper Kuban.

At the level of the Upper Kuban basin geosystem, where the processes take place III between natural, social and man-made components in the natural technical system (NTS) "Natural environment - Object of activity - Population" («NE-AO-P»), in which under «AO» the "Complex of hydraulic structures and related structures" is being considered. Integrity of the considered NTS «NE-AO-P» is provided due to the continuous flow of self-organization and transformation processes in intra-system structural formations (river network, flora and fauna, soil cover, upper layers of the lithosphere and surface layers of the atmosphere, etc.). Implementation of «AO» in «NE» causes certain complications of inter-structural connections in the processes of self-organization between natural and man-made structural formations in the zones of its III. The studies have established that irreversibility in the processes III «AO» with «NE» in the zones of influence leads to the emergence of new phenomena in the geological environment of the upper layers of the lithosphere, in hydrographs and the channel part of the considered section of the river, the coastal strip in the river network floodplain part, the surface layers of the air above water storage facilities and open sections of the water channel and the basin geosystem as a whole (Fig. 1).

Based on the research results analysis of the «AO» identified impacts for «NE» within the spatial limits of the Upper Kuban basin geosystem with the influence zones boundaries' definition, which determined their classification characteristics: low-active, active and strongly-active (Fig. 1), of which the strongly-active zone of influence IV in the section (15

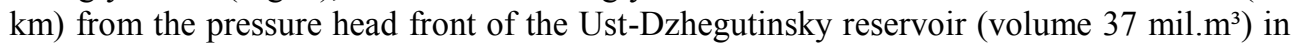
upstream to the alignment (left bank) of Zelenchukskaya HPP-PSPP (Fig. 2), on the one hand, is caused by a change in the natural hydrograph of the Kuban River, and on the other hand, by the Krasnogorsk HPP-1 and HPP-2 under construction with a total volume of 11 million $\mathrm{m}^{3}$, which have a certain impact on the functional work HS pressure front and BSC hydraulic operating mode.

To ensure "environmental safety" in the zone of the Ust-Dzhegutinsky reservoir influence, especially the settlements and the city of Cherkessk located below the section of this reservoir, it became necessary at the first stage of research in the development of a mathematical model for calculating the water flow unsteady movement on the considered a section $(15 \mathrm{~km})$ of a highly active zone of influence IV (Fig. 1), which is caused by water flows discharges from the Zelenchukskaya HPP-PSPP hydroelectric units without taking into account the Krasnogorsk HPP-1 and HPP-2 under construction. 


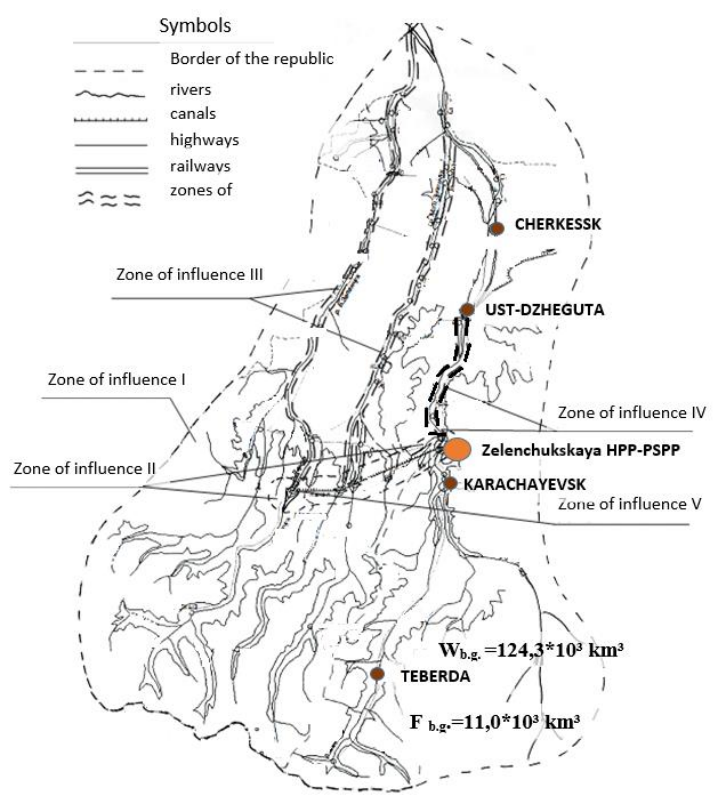

Fig. 1. Zones of hydraulic structures Zelenchuksk HPP complex influence on the environment of the basin geosystem of the Upper Kuban:

I - Inactive zone of influence within the catchment area of the river Kuban upper reaches $\left(11000 \mathrm{~km}^{2}\right)$; II - Active zone of the HS complex influence on microclimate parameters $\left(\mathrm{N}_{\mathrm{mc}}\right)$;

III - Strongly active zone of influence of the complex HS on the rivers B. and M. Zelenchukskaya $\left(\mathrm{N}_{\mathrm{NDO}}\right.$;

IV - Strongly active zone of influence on the $15 \mathrm{~km}$ section of the river Kuban (NUBNE)

$\mathrm{V}$ - Active zone of influence of reservoirs and complex HS on the geological environment (NsRB)

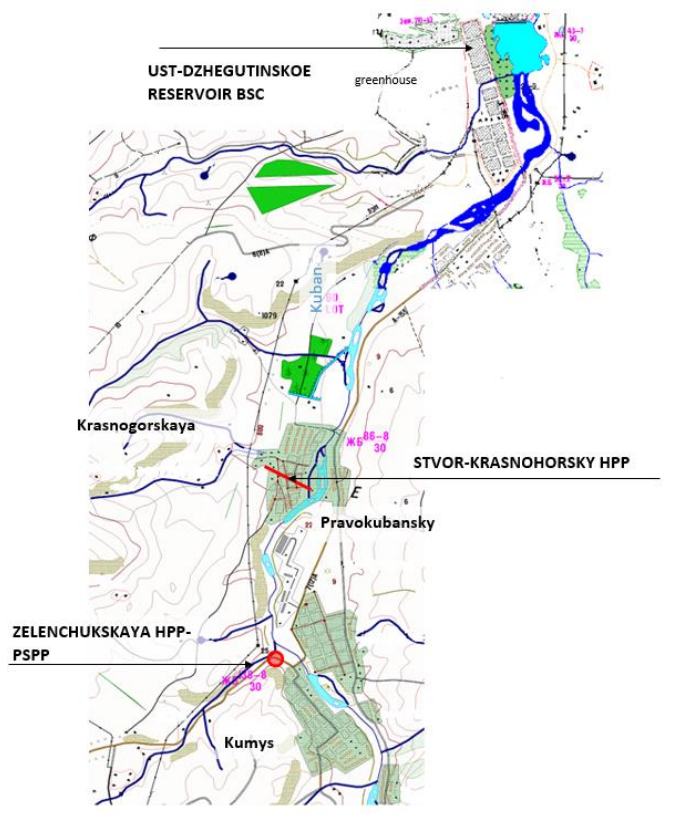

Fig. 2. Situational plan of the Zelenchukskaya HPP-PSPP location and the Ust-Dzhegutinsky reservoir on the Kuban river. 


\section{Mathematical model for calculating unsteady water flow in the area under consideration}

Calculation of water movement in the channel is described using differential equations of unsteady flow of water masses, well developed and studied in hydrodynamics. The model of slowly changing unsteady uneven motion of water masses includes the equations of continuity and momentum. The conservative form of the one-dimensional equation of continuity for river channels with lateral tributaries has the form:

$$
\frac{\partial Q}{\partial x}+\frac{\partial \omega}{\partial t}=q
$$

and in expanded form:

$$
\omega \frac{\partial V}{\partial x}+V \frac{\partial \omega}{\partial x}+\frac{\partial \omega}{\partial t}=q
$$

where: $Q$ - is the water consumption, $\mathrm{m}^{3} / \mathrm{s}$;

$\omega_{-}$is a free area, $\mathbf{M}^{2}$;

$V-$ is an average flow rate, $\mathrm{m} / \mathrm{s}$;

$q$ - is a lateral inflow per unit length, $\mathrm{m}^{2} / \mathrm{s}$;

$x$ and $t-$ are the spatial and temporal coordinates respectively, $\mathrm{m}$ and $\mathrm{s}$.

The expanded form of the one-dimensional momentum equation for the river channels with a lateral tributary has the form:

$$
\frac{\partial V}{\partial t}+V \frac{\partial \omega}{\partial x}+\frac{g}{\omega} \cdot \frac{\partial(\bar{H} \cdot \omega)}{\partial x}+\frac{V \cdot q}{\omega}=g\left(I-I_{f}\right)
$$

where: $g-$ is an acceleration of gravity, $\mathrm{m} / \mathrm{s}^{2}$;

$\bar{H}$ - is the distance from the water surface to the center of water section gravity (in other formulas, instead of it, the flow depth averaged over the section is used);

$I-$ is the river bottom slope, $\mathrm{m} / \mathrm{m}$;

$I_{f}-$ is a hydraulic gradient (friction slope),

$$
I_{f}=\frac{Q^{2}}{K^{2}}
$$

$K=C \omega \sqrt{R_{h}}$ free area ratio to the wetted perimeter) - $R_{h}$, free area $\omega$ and the aspect ratio $C$ (speed coefficient Shezi), associated with the flow speed, as well as the roughness of the channel. There are various formulas for calculating it, taking into account the depth and the roughness coefficient. The latter is tabulated for the main characteristics of the bottom and is widely used in hydraulic calculations.

Continuity equation (1) - (3) can be rewritten as:

$$
\frac{\partial \omega}{\partial t}=-\frac{\partial Q}{\partial x}+q
$$

in the finite-difference interpretation, it is the equation of the channel balance of the site $\Delta x:$ 


$$
\frac{d W}{d t}=-\Delta Q+q \cdot \Delta x
$$

The equation (3.4) (momentum) describes the flow dynamics, characterized by viscosity, slope, roughness and gravitational forces. These parameters, correlated with the flow mass distribution along the channel (channel water balance), make it possible to estimate at any section at a given moment $t$ the hydraulic characteristics we are interested in and, above all, the flow rate, level and flow rate. The equation (3), if there are sufficient data on the hydraulic parameters of the channel based on long-term observations or specially performed instrumental measurements, can be replaced by a relationship $\omega=f(Q, x)$ ( channel capacity curve) and then the continuity equation, if this dependence is substituted into it, will give the desired solution with an acceptable degree of reliability.

If there is an unambiguous relationship $\omega=f(Q, x)$ or $Q=\varphi(\omega, x)$, then the continuity equation in the form (1), (2) or (4) is called the kinematic wave equation (or the mass conservation equation), which makes it possible to use the channel balance models in calculating the unsteady flow in the channel, taking into account a specially selected ratio of finite intervals $\Delta x$ and $\Delta t$ without significant loss of accuracy. Further approbation of the models under the conditions of real observations makes it possible to correct the parameters of the models and, in the future, their use in practice gives quite acceptable results from the point of view of their correctness of application and the obtained accuracy of calculations for specific sections and sections of rivers.

The described equations, taking into account the simplifications made, give sufficiently reliable results if:

- the flow is relatively straightforward and the velocities are approximately the same over the entire open area;

- the pressure across the free flow area obeys the hydrostatic law;

- the river slope is relatively small compared to the length;

- the water flow speed in the channel is determined by the Shezi-Manning formula, i.e., there is a one-digit dependence of water flow rate on level;

- lateral inflow enters the channel normally towards the latter, and its speed does not significantly exceed the speed of the flow itself;

- the lateral inflow value reflects the spatial and temporal variation of the lateral inflow, for the areas without inflows, the component $q=0$.

- a reservoir, if it is included in the general section as a closing section, will stretch along the channel and has an average depth of no more than $3 \mathrm{~m}$, or it is a lake-like pool relatively small in length compared to the total length of the entire calculated section.

\section{Numerical implementation of the unsteady flow propagation model in the area affected by the Zelenchukskaya discharge HPP- PSPP}

To calculate the unsteady uneven water masses movement according to the describing equations (1) - (2), it is necessary to set the initial and boundary conditions at the site. The term "initial conditions" means the state of the flow, its velocity or flow rate at all points of the channel at a time $t=0$. Boundary conditions determine the height of the water layer, its speed or discharge in the upper and lower sections of the river section at any time $t>0$. The linear design scheme of the section under consideration is shown in Fig. 3.

As an initial condition, the uniform steady flow parameters are set. It is described by the flow rate calculated on the basis of the flow rates' current observation data in the section 
of the water post in the village named after Khetagurov, was recalculated taking into account the catchment area in each of the calculated sections $0,1,2,3,4,5,6$. Thus, there are only 7 calculated sections and 6 calculated sections in which the transformation of the input flow entering alignment No. 0 (place of discharge of Zelenchukskaya HPP-PSPP). If the flow at the initial moment of calculation is unsteady, then individual values of flow rates for all sections should be set according to the previous calculation data or should be known (assumed) values. It is considered that if the flow is steady, then the flow rates in the sections of the site are the same and differ only by the correction associated with a slight increase in the catchment area of the sites.

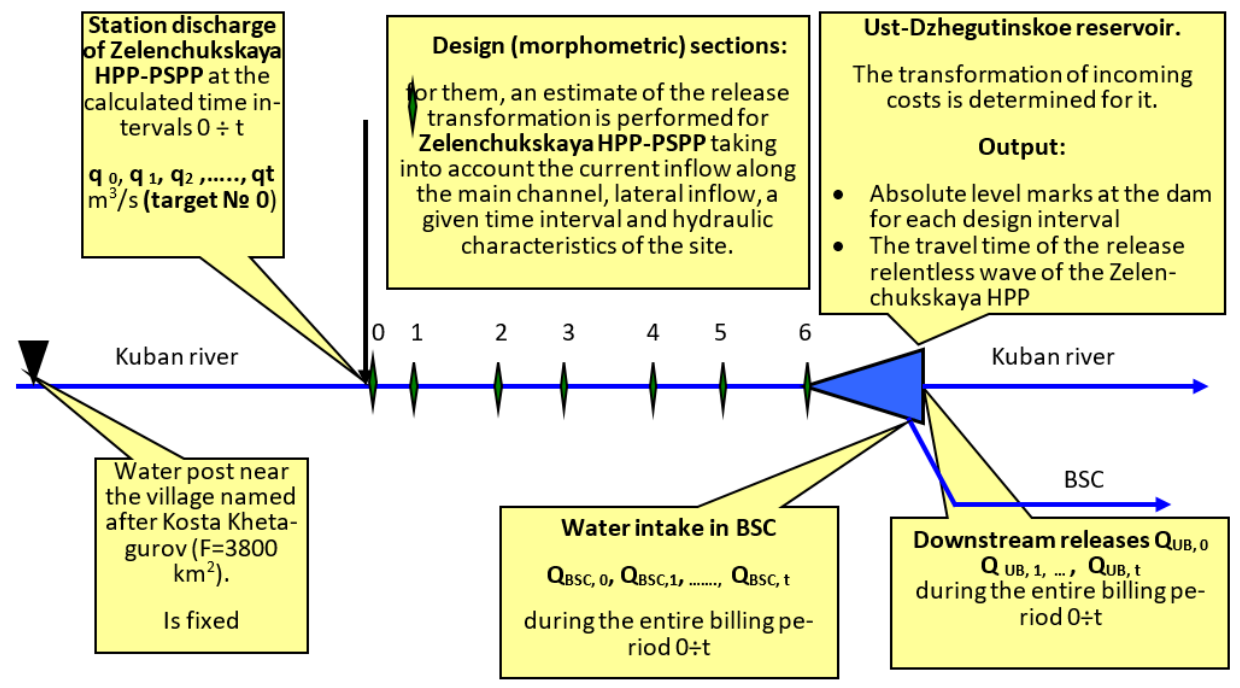

Fig. 3. Calculated linear scheme of the river section Kuban

As the boundary conditions, the values of the incoming flow rates along the river are set in the upper section No. 0. Kuban (according to the settlement of K. Khetagurov, adjusted for the catchment area) plus the discharge by Zelenchukskaya HPP-PSPP. Downstream for every $t$ the flow rates of releases to the Kuban river plus water intake to BSC are set.

For real river channels in the conditions of uneven movement, the cross-sectional area changes along the river (coordinates $x$ ). Unsteady motion entails its change with time, i.e., $\omega=\omega(x, t)$.

However, since the detailed morphometric parameters of river channels are not always available, the averaged characteristics for the sites are used based on the available morphometric data. Thus, the entire site is divided into "characteristic" areas within the limits of which it is considered that the morphometric characteristics are unchanged. At the same time, for the starting point No. 0, the hydrograph is set in accordance with the current hydrological situation and the planned discharge costs of Zelenchukskaya HPP-PSPP:

$$
Q_{0 t}=Q_{0}+q_{t}
$$

where: $Q_{0 t}-$ is the initial survey hydrograph No. 0 , in the intervals $0 \div \mathrm{t}$;

$Q_{0}-$ is a natural hydrograph arriving at site No. 0 , at all intervals $0 \div \mathrm{t}$ (since a short period of up to one day is considered, then it is considered unchanged);

$q_{0}, q_{1}, q_{2}, \ldots . ., q_{t}-$ are the planned discharges of Zelenchukskaya HPP-PSPP at estimated time intervals $0 \div \mathrm{t}, \mathrm{m}^{3} / \mathrm{s}$ 
Next, the flow transformation in the first section and the output hydrograph are calculated, which in turn serves as the input hydrograph for the second section, etc. Such an algorithm makes it possible to significantly simplify the calculation and avoid many mathematical and computational difficulties.

For each "characteristic" section, the equation of the kinematic wave is solved taking into account the agreement of the solution according to the morphometric and slope characteristics known for this section, the roughness and the compiled longitudinal profile, on the basis of which analytical dependences are constructed in the form of piecewise continuous curves:

$Q(H)$ - is the flow dependence in the section on the level;

$H_{a v}(Q)$ - is the average water level dependence on the flow in the section;

$w(Q)$ - is the free area dependence on the flow rate in the section;

$H(Q)$ - is the absolute level mark dependence on the flow rate in the section;

$Q(w)$ - is a flow rate versus cross-sectional area.

The indicated relationship curves were plotted for six available morphometric sections:

- Kuban river, section No. 1 at $950 \mathrm{~m}$ below the territory of Zelenchukskaya HPP-PSPP

- Kuban river, section No. 2 at 3080 m below the territory of Zelenchukskaya HPP-PSPP

- Kuban river section No. 3 at $1090 \mathrm{~m}$ below h/w Krasnogorskaya-Cherkessk bridge

- Kuban river section No. 4 at $246 \mathrm{~m}$ below h/w bridge Krasnogorskaya - Cherkessk

- Kuban river section No. 5 at $2933 \mathrm{~m}$ below h/w bridge Krasnogorskaya - Cherkessk

- Kuban river section No. 6, $24 \mathrm{~m}$ above the cable-stayed crossing of the gas pipeline, $1 \mathrm{~km}$ to the south Vajniy village

In addition, for the Ust-Dzheguta reservoir, transverse profiles have been compiled to more accurately take into account the distribution of the reservoir volume along the length when calculating the dynamic capacity under conditions of unsteady flow rates in the inlet section. The general characteristics of the reservoir are described using the compiled bathygraphic curves:

$F(H)$ - is the reservoir surface area dependence on the level at the dam;

$W(H)$ - is the reservoir volume dependence on the level at the dam;

$H(W)$ - is the level in the reservoir dependence on the volume of filling.

Estimated time interval $\Delta t$ is selected based on the length of the calculated section $\Delta x$ taking into account the travel time of the flow rate $\tau$ at a given flow rate or level at the site, so that $\Delta t$ was close to it, but at the same time $\Delta t \leq \tau$. Otherwise, the calculation by the formula of the kinematic wave gives distorted results - there is, as it were, the effect of a backwater from the side of the downstream section.

On the other hand, $\Delta t$ is set by the experimenter based on the splitting of the entire calculated interval of interest to $T$. If the interval size is set larger than the travel time of the flow rate in accordance with the average flow velocity in the section, then the calculation is performed for a smaller interval for the averaged data, and then the result obtained is generalized for the set larger.

The final result of calculations for "characteristic" sections is generalized for the main 4sections and the Ust-Dzhegutinsky reservoir for the levels at the water intake BSC.

The calculation algorithm is as follows:

1. Calculate the hydrograph $\mathrm{Q}_{\mathrm{i}, \mathrm{t}}$ in alignment $i$ for all calculated time intervals $\mathrm{t}=0,1 \ldots \mathrm{T}$ based on input hydrograph $\mathrm{Q}_{\mathrm{i}-1, \mathrm{t}}$. For the first section, this is the boundary hydrograph, determined by the formula (6).

2. The calculation is performed for the section under consideration for each separate time interval $t$ by solving the equation of propagation of the flow (kinematic wave) from the upper section to the lower in the form (5), as a result of which, we determine the flow rate and level at the end of the current calculated time interval. 
3. According to the hydraulic connection formulas, we determine the remaining hydraulic characteristics, taking into account the test connections. At the same time, we determine the discrepancy arising when calculating the average level in the lower section of the section. Taking this into account, we make a series of iterative clarifying calculations, as a result of which we determine for the section under consideration the final values of the flow rate and level at the end of the interval $t$ (and, accordingly, at the beginning of the interval $\mathrm{t}+1)$ : $\mathrm{Q}_{\mathrm{i},(\mathrm{t}+1)}, \mathrm{H}_{\mathrm{i},(\mathrm{t}+1) \text {. }}$

4. On the next calculation interval $t+1$ obtained at the previous time step $\mathrm{Q}_{\mathrm{i}, t+1}$, we consider the lower boundary flow rate, and the upper boundary flow rate - $\mathrm{Q}_{(\mathrm{i}-1)(\mathrm{t}+1)}$ and continue the calculation according to the previous paragraphs 2 and 3 until all time intervals have been exhausted.

5. The design sequence 1-4 is performed sequentially for all sections and downstream. At the end of the calculation, we take the obtained calculated hydrographs and the corresponding levels in the sections as the sought solution for finding the costs and levels. The algorithm for such a calculation is implemented as a program for PC and was used to develop dispatching rules for the management of the combined water-management system BSC and Zelenchukskaya HPP-PSPP and create WKS.

\section{Conclusion}

In the systematic study of III «Activity Object» processes as a part of NTS «NE-AO-P» it was found that the criterial quantitative indicator $\left(\mathrm{N}_{\mathrm{j}}\right)$ for the considered highly active zone of influence IV in the section from Zelenchukskaya HPP-PSPP to the structures of the pressure front of the Ust-Dzhegutinsky reservoir in quantitative terms is determined by the ratio of the local spatial limits of the highly active influence zone IV to the spatial limits of the basin geosystem of the Upper Kuban, where water resources and indicator $\mathrm{N}_{\mathrm{j}}=\mathrm{W}_{\mathrm{IV}} / \mathrm{W}_{\mathrm{BGUK}}=0,0008(0,08 \%)$, which is $0.08 \%$, which determines the dominance of natural processes between the components NTS «NE-AO-P» and, accordingly, "environmental safety".

The developed mathematical model can be implemented as a PC program for the development of dispatching rules for the management of the combined BSC system and Zelenchukskaya HPP-PSPP.

\section{References}

1. Yu.A. Afanasyev, Monitoring and methods of environmental control: P. 1 (Moscow, International independent ecological and political university, 1998).

2. V.L Bondarenko, Nature management: territories of basin geosystems: textbook (Rostov-on-Don, Publishing Center "Mart", 2010).

3. V.L Bondarenko, G.M. Skibin, V.N. Azarov, E.A. Semenova, V.V. Privalenko, Environmental safety in environmental management, water use and construction: assessment of the ecological state of basin geosystems, Monograph Platov SouthRussian State Polytechnic University (NPI), Novocherkassk: SRSPU (NPI), 2016.

4. V.L Bondarenko, O.V. Klimenko, E.A. Semenova, D.A. Nikolaenko, Environmental safety in construction. Engineering and environmental surveys in the complex of surveys for the construction of water facilities: monograph (Novocherkassk Engineering and Reclamation Institute named after A. K. Kortunov; Don State Agrarian University, Novocherkask, 2016).

5. V.L Bondarenko, E.A. Semenova, A.V. Aliferov, O.V. Klimenko, Natural and technical 
systems in the use of water resources: territories of basin geosystems: monograph (Novocherkassk: SRSPU (NPI), 2016).

6. V.L Bondarenko, V.V. Gutenev, V.V. Privalenko, E.S. Polyakov, Theoretical and Applied Ecology 1, 47-54 (2007).

7. M.I. Budyko, O.A. Drozdov, Questions of hydrometeorological efficiency of field protection afforestation (Guide-rosmeteoizdat, Leningrad, 1950).

8. S.L. Vendrov, On the issue of research of interaction of large hydroelectric facilities and water management systems with the environment (Hydro project works, Moscow, 1979).

9. R. Ged Davis, Energy for the planet Earth. In the world of science 11, 7-16 (1990).

10. N.N. Moiseev, Man and noosphere (Young Guard, Moscow, 1992).

11. G. Nicolis, I. Prigogine, Self-organization in nonequilibrium systems (Mir, Moscow, 1979).

12. G. Nicolis, I. Prigogine, Knowledge of the Complex Mir, Moscow, 1990).

13. A.M. Chernyaev, Russia: Introductory resource potential (Yekaterinburg, 1998).

14. E.D. Khetsuriani, V.L. Bondarenko, A.I. Ylyasov, E.A. Semenova, Development of protective measures providing environmental safety in areas affected by water-intake constructions of urban households, IOP Conference Series: Materials Science and Engineering 698, 077053 (International Scientific Conference "Construction and Architecture: Theory and Practice of Innovative Development") 1-5 October 2019, Kislovodsk, Russia (2019) https://iopscience.iop.org/article/10.1088/1757899X/698/7/077053/pdf

15. E.D. Khetsuriani, V.L. Bondarenko, A.I. Ylyasov, E.A. Semenova, Evaluation of environmental safety of waterworks for urban water supply systems, IOP Conference Series: Materials Science and Engineering 698 (7), 077060 (2019). International Scientific Conference "Construction and Architecture: Theory and Practice of Innovative Development", 1-5 October 2019, Kislovodsk, Russian Federation. URL: https://iopscience.iop.org/article/10.1088/1757-899X/698/7/077060/pdf

16. E.D. Khetsuriani, V.L. Bondarenko, A.I. Ylyasov, E.A. Semenova, Innovative design solutions to ensure the environmental safety in the existing water intake technological complexes of water systems for urban farms, IOP Conference Series: Materials Science and Engineering 698, 055040 (International Scientific Conference "Construction and Architecture: Theory and Practice of Innovative Development") 1-5 October 2019, Kislovodsk, Russia (2019) https://iopscience.iop.org/article/10.1088/1757899X/698/5/055040/pdf

17. E.D. Khetsuriani, V.L. Bondarenko, A.I. Ylyasov, E.A. Semenova, Lightweight constructions in technical water supply systems of thermal and nuclear power plants, IOP Conference Series: Materials Science and Engineering 698, 055042 (International Scientific Conference "Construction and Architecture: Theory and Practice of Innovative Development") 1-5 October 2019, Kislovodsk, Russia (2019) https://iopscience.iop.org/article/10.1088/1757-899X/698/5/055042/pdf

18. E.D. Khetsuriani, V.L. Bondarenko, N.A. Polianskii, Methodological Bases of Creation and Development of a New Type of Natural and Technical Systems of Multipurpose Water Use in Urban Areas [Electronic resource], IOP Conference Series: Earth and Environmental Science 272, 022225 (2019). International science and technology conference "Earth science" 4-6 March 2019, Russky Island, Russian Federation. Access mode: https://iopscience.iop.org/article/10.1088/1755-1315/272/2/022225/pdf. 